\title{
Field Devices For Monitoring Soil Water Content ${ }^{1}$
}

Rafael Muñoz-Carpena ${ }^{2}$

\section{Introduction}

In the context of water management for irrigation, measuring and monitoring soil water status is an essential component of best management practices (BMPs) to improve the sustainability of agriculture.

Water content in the soil can be directly determined using the difference in weight before and after drying a soil sample. This direct technique is usually referred to as the thermo-gravimetric method (or simply gravimetric) when expressing water content as weight of water over weight of dry soil, GWC $\left[1 b^{3} b^{-3}\right]$ (i.e., the ratio of the mass of water present in a sample to the mass of the soil sample after it has been oven-dried $\left(100-110^{\circ} \mathrm{C}\right)$ to a constant weight). On the other hand, the thermovolumetric method (or simply volumetric) gives the water content as volume of water in a volume of undisturbed soil VWC $\left[\mathrm{ft}^{3} \mathrm{ft}^{-3}\right]$ (i.e., volume of water related to the volume of an oven-dried undisturbed sample (soil core)). Although these direct methods are accurate $\left( \pm 0.01 \mathrm{ft}^{3} \mathrm{ft}^{-3}\right)$ and inexpensive, they are destructive, slow (2 days minimum), timeconsuming and do not allow for making repetitions in the same location. Alternatively, many indirect methods are available for monitoring soil water content. These methods estimate soil moisture by a calibrated relationship with some other measurable variable. The suitability of each method depends on several issues like cost, accuracy, response time, installation, management and durability.
Depending on the quantity measured, indirect techniques are first classified into volumetric and tensiometric methods (Fig. 1). While the former gives volumetric soil moisture, the latter yields soil suction or water potential (i.e., tension exerted by capillarity). Both quantities are related through the soil water characteristic curve specific to a given soil.



Figure 1. Methods for soil moisture measuring.

It is important to remember that each soil type (texture/structure) has a different curve; therefore, they cannot be related to each other the same way for all soil types (Fig. 2). In addition, this relationship might not be unique and may differ along drying and wetting cycles, especially in finer soils. Several mathematical equations have been proposed to describe the soil characteristic curve that can help to calculate water needed for irrigation.

\footnotetext{
${ }^{1}$ This document is Bulletin 343, one of a series from the Department of Agricultural and Biological Engineering, Florida Cooperative Extension Service, Institute of Food and Agricultural Sciences, University of Florida. First published: July 2004. This document replaces in part CIR 532. Please visit the EDIS Web site at http://edis.ifas.ufl.edu

${ }^{2}$ Rafael Muñoz-Carpena, Assistant Professor, Department of Agricultural and Biological Engineering, Florida Cooperative Extension Service, Institute of Food and Agricultural Sciences, IFAS/TREC, University of Florida, Homestead, FL 33031.

The Institute of Food and Agricultural Sciences (IFAS) is an Equal Employment Opportunity - Affirmative Action Employer authorized to provide research, educational information and other services only to individuals and institutions that function without regard to race, creed, color, religion, age, disability, sex, sexual orientation, marital status, national origin, political opinions or affiliations. For information on obtaining other extension publications, contact your county Cooperative Extension Service office. Florida Cooperative Extension Service/Institute of Food and Agricultural Sciences/University of Florida/Larry R. Arrington, Interim Dean
} 


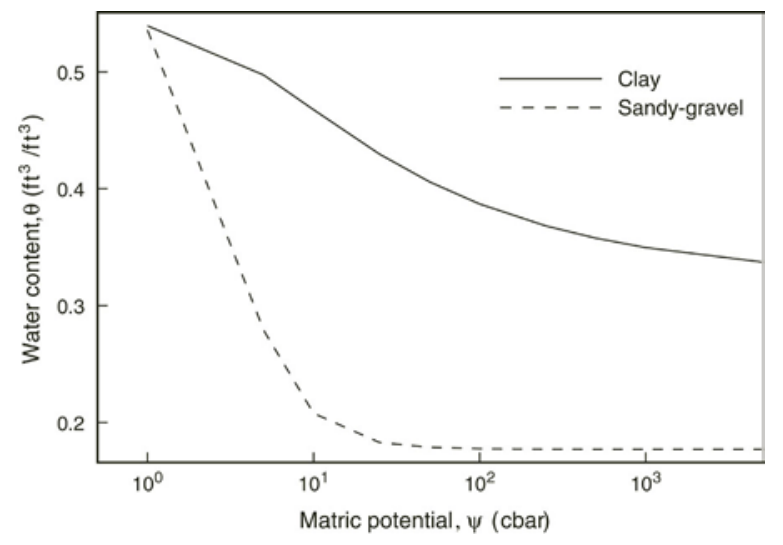

Figure 2. Measured soil characteristic curves for two different soil types.

Depending on the soil physical properties and goal of the soil moisture measurement, some devices are more effective than others. Firstly, it must be considered that although volumetric moisture is a more intuitive quantity, in fine texture soils water is strongly retained by solid particles and therefore may not be available for plant absorption and other processes like flow. In the case of plant-soil studies, soil suction may be a more useful quantity since it relates to the energy that plants have to invest to extract the water from the soil, and hence it is a more meaningful measure of plant water stress. Secondly, the desired sampling frequency is an important factor since response times of different sensors vary over a wide range (i.e.,some devices require soil moisture to equilibrate with the sensor matrix). Thirdly, soil physical properties (texture, shrinking/swelling) may influence the suitability of the selected method, because some of them require good soil-instrument contact. On the other hand, depending on soil type and hydrologic conditions (precipitation and evapotranspiration), some instruments might have higher maintenance requirements than others.

Irrigation management is a practical application of monitoring soil moisture that is becoming widespread among agricultural growers. Soil moisture-based optimized irrigation consists of keeping the soil within a target moisture range by replenishing the plant water uptake with irrigation. This practice reduces the potential for soil water excess and leaching of agrochemicals present in the soil, however it requires selection of a suitable method for soil moisture estimation (MuñozCarpena et al., 2002; 2003). To calculate irrigation requirements (the amount of water that needs to be applied with each irrigation), suction values from tensiometric methods need to be converted to soil moisture through the soil characteristic curve.

\section{Field Methods for Soil Moisture Measurement: Trade-offs. Comparative Study}

Most practical techniques for soil water monitoring are indirect (Yoder et al., 1998; Robinson et al., 1999). A review of available techniques is given below, focusing on working principles, advantages and drawbacks.

\section{Volumetric Field Methods}

All methods under this definition estimate the volume of water in a sample volume of undisturbed soil $\left[\mathrm{ft}^{3} \mathrm{ft}^{-3}\right]$. This quantity is useful for determining how saturated the soil is (i.e.,fraction of total soil volume filled with the soil aqueous solution). When it is expressed in terms of depth (i.e.,volume of water in soil down to a given depth over a unit surface area (inches of water)), it can be compared with other hydrological variables like precipitation, evaporation, transpiration, deep drainage, etc.

\section{Neutron Moderation}

Working principle: Fast neutrons are emitted from a decaying radioactive source $\left({ }^{241} \mathrm{Am} /{ }^{9} \mathrm{Be}\right)$ and when they collide with particles having the same mass as a neutron (i.e., protons, $\mathrm{H}^{+}$), they slow down dramatically, building a "cloud" of "thermalized" (slowed-down) neutrons. Since water is the main source of hydrogen in most soils, the density of slowed-down neutrons formed around the probe is nearly proportional to the volume fraction of water present in the soil.

Description: The probe configuration is in the form of a long and narrow cylinder, containing a source and detector. Measurements are made by introducing the probe into an access tube (previously installed into the soil). It is possible to determine soil moisture at different depths by hanging the probe in the tube at different depths (Fig. 3). The soil moisture is obtained from the device based on a linear calibration between the count rate of slowed-down neutrons at the field 
(read from the probe), and the soil moisture content obtained from nearby field samples.

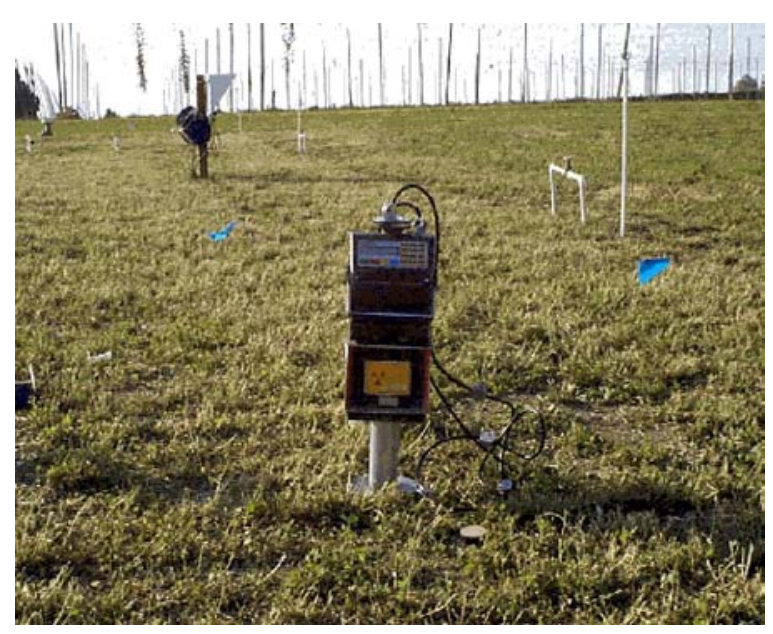

Figure 3. Neutron probe.

\section{Advantages}

- $\quad$ Robust and accurate $\left( \pm 0.005 \mathrm{ft}^{3} \mathrm{ft}^{-3}\right)$

- Inexpensive per location (i.e., a large number of measurements can be made at different points with the same instrument)

- One probe allows for measuring at different soil depths

- Large soil sensing volume (sphere of influence with 4-16 in. radius, depending on moisture content)

- Not affected by salinity or air gaps

- Stable soil-specific calibration

\section{Drawbacks}

- Safety hazard, since it implies working with radiation. Even at 16 in. depth, radiation losses through soil surface have been detected

- Requires certified personnel

- Requires soil-specific calibration

- Heavy, cumbersome instrument

- Takes relative long time for each reading

- Readings close to the soil surface are difficult and not accurate

- Manual readings; cannot be automated due to hazard

- $\quad$ Expensive to buy
- The sphere of influence may vary according to the following reasons:

a) it increases as the soil dries, because the hydrogen concentration reduces, so that the probability of collision is smaller and thereby fast neutrons can travel further from the source

b) it is smaller in fine texture soils, because they can hold more water, thus the probability of collision is higher

c) if there are layers with large differences in water content due to changes in soil physical properties, the sphere of influence can have a distorted shape

\section{Dielectric Methods}

The next set of volumetric methods is known as dielectric techniques. They estimate soil water content by measuring the soil bulk permittivity (or dielectric constant), $\mathrm{Ka}_{b}$, that determines the velocity of an electromagnetic wave or pulse through the soil. In a composite material like the soil (i.e., made up of different components like minerals, air and water), the value of the permittivity is made up by the relative contribution of each of the components. Since the dielectric constant of liquid water $\left(\mathrm{Ka}_{w}=81\right)$ is much larger than that of the other soil constituents (e.g. $\mathrm{Ka}_{s}=2-5$ for soil minerals and 1 for air), the total permittivity of the soil or bulk permittivity is mainly governed by the presence of liquid water.

A common approach to establish the relationship between $\mathrm{Ka}_{b}$ and volumetric soil moisture (VWC) is the empirical equation of Topp et al. (1980):

$$
\begin{aligned}
\mathrm{VWC}= & -5.3 \cdot 10^{-2}+2.29 \cdot 10^{-2} \mathrm{Ka}_{b}-5.5 \cdot 10^{-4} \mathrm{Ka}_{b}{ }^{2}+ \\
& 4.3 \cdot 10^{-6} \mathrm{Ka}_{b}{ }^{3}
\end{aligned}
$$

This relationship works for most mineral soils (independent of soil composition and texture) and for moisture below 50\%. For larger water content, organic or volcanic soils, a specific calibration is required. It is worth noticing that the relationship depends on the electromagnetic wave frequency sent by the specific device. At low frequencies $(<100 \mathrm{MHz})$ it is more soil-specific. 
The dielectric methods described below use empirical calibrated relationships between VWC and the sensor output signal (time, frequency, impedance, wave phase). These techniques are becoming widely adopted because they have good response time (almost instantaneous measurements), do not require maintenance, and can provide continuous readings through automation.

\section{Time Domain Reflectometry (TDR)}

Working principle: The soil bulk dielectric constant $\left(\mathrm{Ka}_{b}\right)$ is determined by measuring the time it takes for an electromagnetic pulse (wave) to propagate along a transmission line (TL) that is surrounded by the soil. Since the propagation velocity $(v)$ is a function of $\mathrm{Ka}_{b}$, the latter is therefore proportional to the square of the transit time ( $t$, in seconds) down and back along the TL:

$\mathrm{Ka}_{b}=(c / v)^{2}=((c . t) /(2 . L))^{2}$

where $c$ is the velocity of electromagnetic waves in a vacuum $\left(3 \cdot 10^{8} \mathrm{~m} / \mathrm{s}\right.$ or $\left.186,282 \mathrm{mile} / \mathrm{s}\right)$ and $L$ is the length of the TL embedded in the soil (in $\mathrm{m}$ or $\mathrm{ft}$ ).

Description: A TDR instrument (Fig. 4) requires a device capable of producing a series of precisely timed electrical pulses with a wide range of high frequencies used by different devices (e.g., 0.02-3 $\mathrm{GHz}$ ), which travel along a TL that is built with a coaxial cable and a probe. This high frequency provides a response less dependent on soil specific properties like texture, salinity or temperature. The TDR probe usually consists of 2-3 parallel metal rods that are inserted into the soil acting as waveguides in a similar way as an antenna used for television reception. At the same time, the TDR instrument uses a device for measuring and digitizing the energy (voltage) level of the TL at intervals down to around 100 picoseconds. When the electromagnetic pulse traveling along the TL finds a discontinuity (i.e., probe-waveguides surrounded by soil) part of the pulse is reflected. This produces a change in the energy level of the TL. Thereby the travel time $(t)$ is determined by analyzing the digitized energy levels.

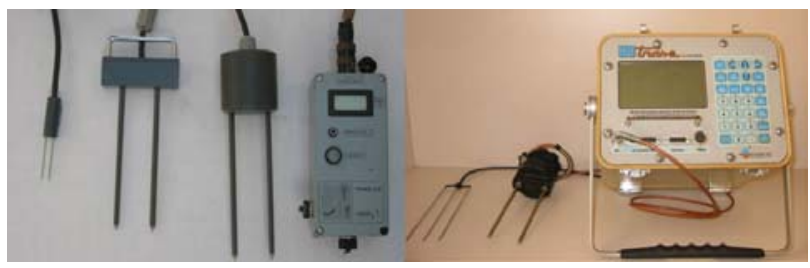

Figure 4. TDR equipment.

Soil salinity or highly conductive heavy clay contents may affect TDR, since it contributes to attenuation of the reflected pulses. In other words, TDR is relatively insensitive to salinity as long as a useful pulse is reflected (i.e., as long as it can be analyzed). In soils with highly saline conditions, using epoxy-coated probe rods should solve the problem. However, this implies loss of sensitivity and change in calibration. It is interesting to notice that in addition to time of travel another characteristic of the pulse traveling through the soil (i.e., change in size or attenuation of the pulse) can be related to the soil electrical conductivity. Based on this some commercial devices incorporate the possibility of measuring water content and soil salinity simultaneously.

\section{Advantages}

- Accurate $\left( \pm 0.01 \mathrm{ft}^{3} \mathrm{ft}^{-3}\right)$

- Soil specific-calibration is usually not required

- $\quad$ Easily expanded by multiplexing

- Wide variety of probe configurations

- Minimal soil disturbance

- Relatively insensitive to normal salinity levels

- Can provide simultaneous measurements of soil electrical conductivity.

\section{Drawbacks}

- Relatively expensive equipment due to complex electronics

- Potentially limited applicability under highly saline conditions or in highly conductive heavy clay soils

- Soil-specific calibration required for soils having large amounts of bound water (i.e., those with high organic matter content, volcanic soils, etc.)

- $\quad$ Relatively small sensing volume (about 1.2 inch radius around length of waveguides) 


\section{Frequency Domain (FD): Capacitance and FDR}

Working principle: The electrical capacitance of a capacitor that uses the soil as a dielectric depends on the soil water content. When connecting this capacitor (made of metal plates or rods imbedded in the soil) together with an oscillator to form an electrical circuit, changes in soil moisture can be detected by changes in the circuit operating frequency. This is the basis of the Frequency Domain (FD) technique used in Capacitance and Frequency Domain Reflectometry (FDR) sensors. In Capacitance sensors the dielectric permittivity of a medium is determined by measuring the charge time of a capacitor made with that medium. In FDR the oscillator frequency is swept under control within a certain frequency range to find the resonant frequency (at which the amplitude is greatest), which is a measure of water content in the soil.

Description: Probes usually consist of two or more electrodes (i.e., plates, rods, or metal rings around a cylinder) that are inserted into the soil. On the ring configuration the probe is introduced into a access tube installed in the field. Thus, when an electrical field is applied, the soil around the electrodes (or around the tube) forms the dielectric of the capacitor that completes the oscillating circuit. The use of an access tube allows for multiple sensors to take measurements at different depths (Fig. 5).

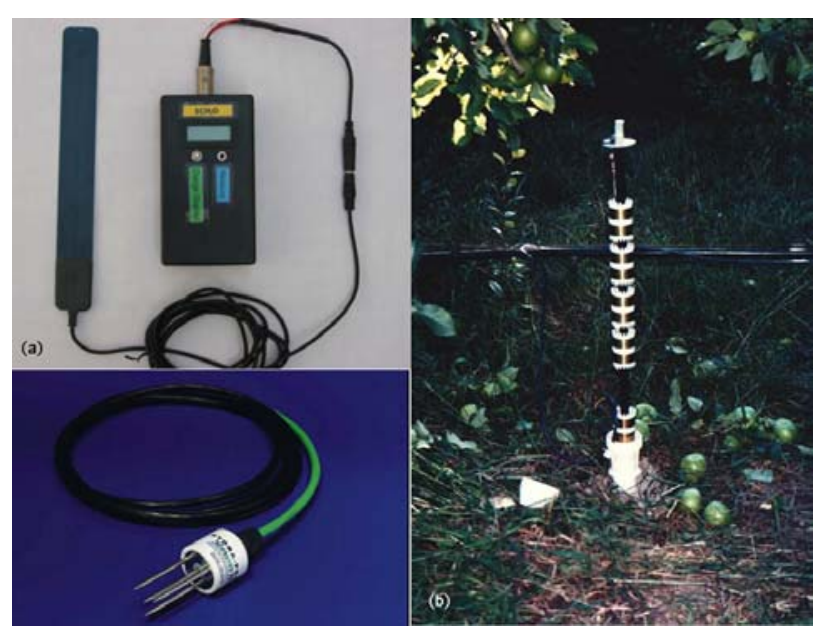

Figure 5. FD probes: a) Capacitance (plates imbibed in a silicon board); b) Capacitance (rods); and c) FDR (rings).
A soil-specific calibration is recommended because the operating frequency of these devices is generally below $100 \mathrm{MHz}$. At these low frequencies the bulk permittivity of soil minerals may change and the estimation is more affected by temperature, salinity, bulk density and clay content.

\section{Advantages}

- Accurate after soil-specific calibration $\left( \pm 0.01 \mathrm{ft}^{3} \mathrm{ft}^{-3}\right)$

- Can read in high salinity levels, where TDR fails

- Better resolution than TDR (avoids the noise that is implied in the waveform analysis performed by TDRs)

- Can be connected to conventional loggers (DC output signal)

- Flexibility in probe design (more than TDR)

- Some devices are relatively inexpensive compared to TDR due to use of low frequency standard circuitry

\section{Drawbacks}

- The sensing sphere of influence is relatively small (about 1.6 in.)

- For reliable measurements, it is extremely critical to have good contact between the sensor (or tube) and soil

- Careful installation is necessary to avoid air gaps

- Tends to have larger sensitivity to temperature, bulk density, clay content and air gaps than TDR

- Needs soil-specific calibration

\section{Amplitude Domain Reflectometry (ADR): Impedance}

Working principle: When an electromagnetic wave (energy) travelling along a transmission line (TL) reaches a section with different impedance (which has two components: electrical conductivity and dielectric constant), part of the energy transmitted is reflected back into the transmitter. The reflected wave interacts with the incident wave producing a voltage standing wave along the TL, i.e. change of wave amplitude along the length of the TL. If the soil/probe combination is the cause for the impedance change in the TL, measuring the amplitude difference will give the impedance of the probe (Gaskin and Miller, 1996; Nakashima et al., 1998). The influence of the soil electrical 
conductivity is minimized by choosing a signal frequency, so that the soil water content can be estimated from the soil/probe impedance.

Description: Impedance sensors use an oscillator to generate a sinusoidal signal (electromagnetic wave at a fixed frequency, e.g., $100 \mathrm{MHz}$ ) that is applied to a coaxial TL that extends into the soil through an array of parallel metal rods, the outer of which forms an electrical shield around the central signal rod (Fig. 6). This rod arrangement acts as an additional section of the TL, having impedance that depends on the dielectric constant of the soil between the rods.
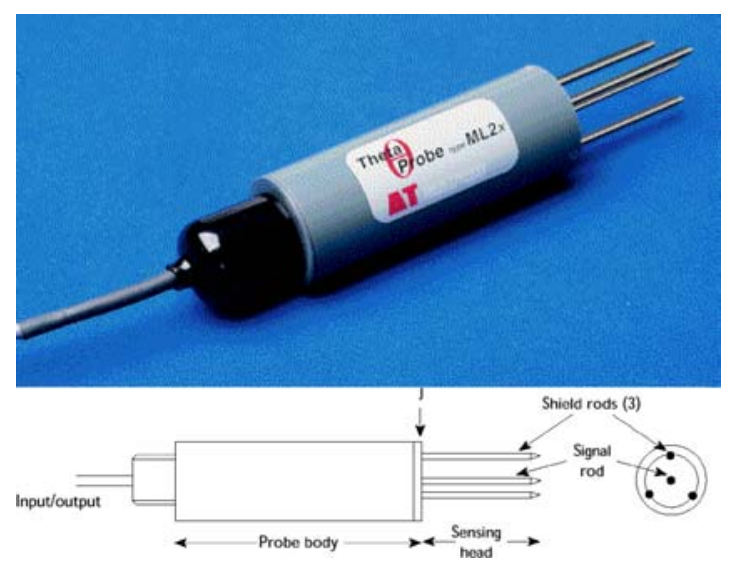

Figure 6. ADR probe.

Advantages

- Accurate with soil-specific calibration $\left( \pm 0.01 \mathrm{ft}^{3} \mathrm{ft}^{-3} ; \pm 0.05 \mathrm{ft}^{3} \mathrm{ft}^{-3}\right.$ without it)

- Allows measurements in highly saline conditions (up to $20 \mathrm{dS} / \mathrm{m}$ ).

- Minimal soil disturbance

- Can be connected to conventional loggers (DC output signal)

- Inexpensive due to standard circuitry

- Not affected by temperature

- In situ estimation of soil bulk density possible (Wijaya et al., 2002)

Drawbacks

- Soil-specific calibration recommended for reliable measurements

- Measurement affected by air gaps, stones or channeling water directly onto the probe rods

- $\quad$ Small sensing volume $\left(0.27 \mathrm{in}^{3}\right)$

\section{Phase Transmission (Virrib)}

Working principle: After having travelled a fixed distance, a sinusoidal wave will show a phase shift relative to the phase at the origin. This phase shift depends on the length of travel along the TL, the frequency and the velocity of propagation. Since velocity of propagation is related to soil moisture content, for a fixed frequency and length of travel soil water content can be determined by this phase shift.

Description: The probe uses a particular waveguide design (two open concentric metal rings), so that phase measuring electronics can be applied at the beginning and ending of the waveguides (Fig. 7).

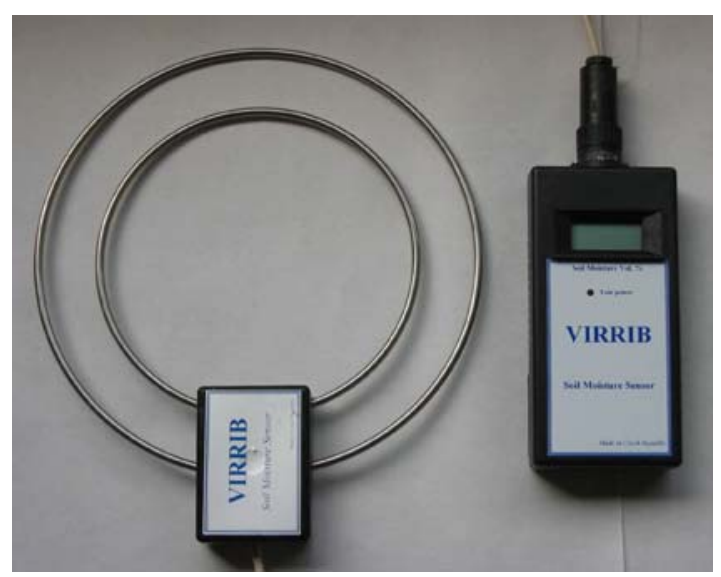

Figure 7. Phase transmission probe.

\section{Advantages}

- Accurate with soil-specific calibration $\left( \pm 0.01 \mathrm{ft}^{3} \mathrm{ft}^{-3}\right)$

- Large sensing soil volume (4-5 gallons)

- Can be connected to conventional loggers (DC output signal)

- Inexpensive

\section{Drawbacks}

- $\quad$ Significant soil disturbance during installation due to concentric rings sensor configuration

- Requires soil-specific calibration

- Sensitive to salinity levels $>3 \mathrm{dS} / \mathrm{m}$

- Reduced precision, because the generated pulse gets distorted during transmission

- Needs to be permanently installed in the field 


\section{Time Domain Transmission (TDT)}

Working principle: This method measures the one-way time for an electromagnetic pulse to propagate along a transmission line (TL). Thus, it is similar to TDR, but requires an electrical connection at the beginning and ending of the TL. Notwithstanding, the circuit is simple compared with TDR instruments.

Description: The probe has a waveguide design (bent metal rods), so that the beginning and ending of the transmission line are inserted into the electronic block. Alternatively, the sensor consists of a long band $(\sim 3 \mathrm{ft})$, having an electronic block at both ends (Fig. 8).

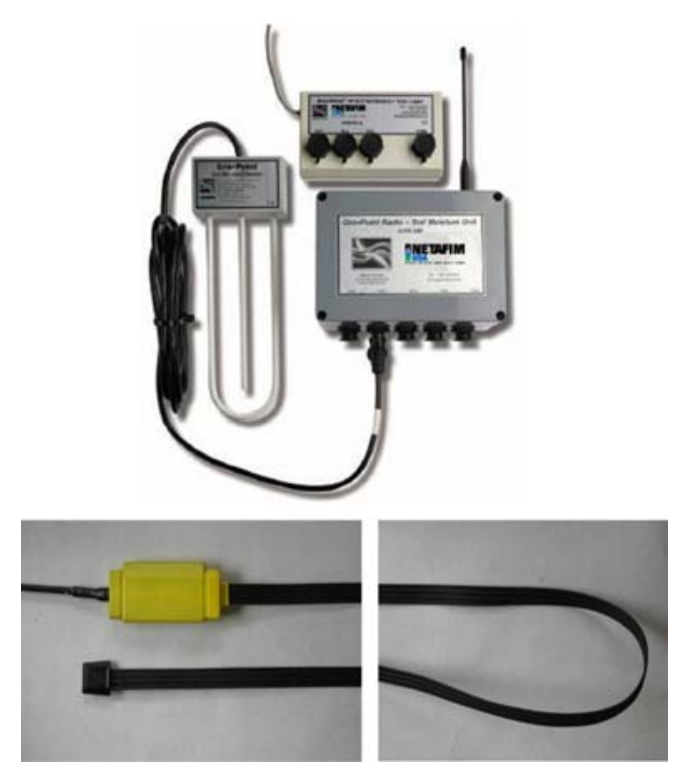

Figure 8. TDT probe.

Advantages

- Accurate $\left( \pm 0.01-0.02 \mathrm{ft}^{3} \mathrm{ft}^{-3}\right)$

- Large sensing soil volume (0.2-1.6 gallons)

- Can be connected to conventional loggers (DC output signal)

- Inexpensive due to standard circuitry

Drawbacks

- $\quad$ Reduced precision, because the generated pulse is distorted during transmission

- Soil disturbance during installation

- Needs to be permanently installed in the field

\section{Other Volumetric Field Methods}

Another interesting technique is the Ground Penetrating Radar (GPR). This technique is based on the same principle as TDR, but does not require direct contact between the sensor and the soil. When mounted on a vehicle or trolley close to the soil surface, it has the potential of providing rapid, non-disturbing, soil moisture measurements over relatively large areas, whereas TDR is better for detailed measurements over small areas. Although it has been applied successfully to many field situations, GPR has not been widely used because the methodology and instrumentation are still only in the research and development phase (Davis and Annan, 2002). It is however likely that small, compact and inexpensive GPR systems will be available in the near future for routine field studies.

Mention should also be made of new remote sensing (non-contact) methods specially suited for soil moisture monitoring over large areas, usually mounted on airplanes or satellites. Among these methods, the active and passive microwave, and electromagnetic induction (EMI) methods have been found useful in different applications (Dane and Topp, 2002), and are the subject of much current research. The active and EMI methods use two antennae to transmit and receive electromagnetic signals that are reflected by the soil, whereas the passive microwave just receives signals naturally emitted by the soil surface. On the microwave methods, typically the signal relates to some shallow depth below the ground surface $(<4$ in) so that only a measure of the soil moisture and electrical conductivity of the near-surface soil can be achieved. EMI does not measure water content directly, but rather soil electrical conductivity, and a known calibration relationship between the two is required. Unfortunately, this relationship is sitespecific and cannot be assumed.

Other modern techniques for estimating soil moisture and flow are $\mathrm{x}$-ray tomography and nuclear magnetic resonance (NMR). However, their application to field conditions is limited. The reader is referred to other publications for further details (see, e.g., Alvarez-Benedi and MuñozCarpena, 2004). 


\section{Tensiometric Field Methods}

Tensiometric methods estimate the soil water matric potential that includes both adsorption and capillary effects of the soil. The matric potential is one of the components of the total soil water potential that also includes gravitational (position with respect to a reference elevation plane), osmotic (salts in soil solution), gas pressure or pneumatic (from entrapped air), and overburden components. The sum of matric and gravitational potentials is the main driving force for water movement in soils and other soil-like porous media.

All available tensiometric instruments have a porous material in contact with the soil, through which water can move. Thereby, water is drawn out of the porous medium in a dry soil and from the soil into the medium in a wet soil. It is worth noticing, that in general, they do not need a soil specific calibration, however, in most cases they have to be permanently installed in the field, or a sufficiently long time must be allowed for equilibration between the device and the soil before making a reading.

\section{Tensiometer}

Working principle: When a sealed water-filled tube is placed in contact with the soil through a permeable and saturated porous material, water (inside the tube) comes into equilibrium with the soil solution (i.e., it is at the same pressure potential as the water held in the soil matrix). Hence, the soil water matric potential is equivalent to the vacuum or suction created inside the tube.

Description: The tensiometer consists of a sealed water-filled plastic tube with a ceramic cup at one end and a negative pressure gauge (vacuometer) at the other. The shape and size of the ceramic cup can be variable and the accuracy depends on the gauge or transducer used (about 0.01 bar). Typically the measurement range is $0-0.80$ bar, although there are low-tension versions (0-0.40 bar) designed for coarse soils (Fig. 9).

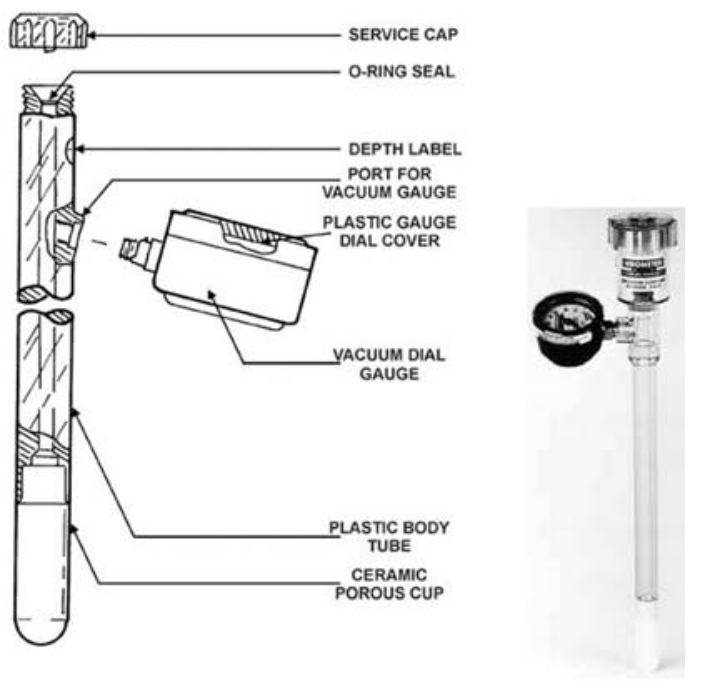

Figure 9. Tensiometer.

\section{Advantages}

- Direct reading

- Up to 4 inch measurement sphere radius

- Continuous reading possible when using pressure transducer

- Electronics and power consumption avoidable

- Well-suited for high frequency sampling or irrigation schedules

- Minimal skill required for maintenance

- Not affected by soil salinity, because salts can move freely in and out across the porous ceramic cup

- Inexpensive

Drawbacks

- Limited soil suction range $(<1$ bar $)$

- Relatively slow response time

- Requires intimate contact with soil around the ceramic cup for consistent readings and to avoid frequent discharge (breaking of water column inside)

- Especially in swelling or coarse soils, the ceramic cup can loose contact with soil, thus requiring reinstallation

- Requires frequent maintenance (refilling) to keep the tube full of water, specially in hot dry weather 


\section{Resistance Blocks}

Working principle: The electrical resistance between electrodes embedded in a porous medium (block) is proportional to its water content, which is related to the soil water matric potential of the surrounding soil. Electrical resistance reduces as the soil, hence the block, dries.

\section{Gypsum (Bouyoucos) Block}

Description: A gypsum block sensor constitutes an electrochemical cell with a saturated solution of calcium sulphate as electrolyte. The resistance between the block-embedded electrodes is determined by applying a small $\mathrm{AC}$ voltage (to prevent block polarization) using a Wheatstone bridge. Since changes to the soil electrical conductivity would affect readings, gypsum is used as a buffer against soil salinity changes (up to a certain level). The inherent problem is that the block dissolves and degrades over time (especially in saline soils) losing its calibration properties. It is recommended that the block pore size distribution match the soil texture being used. The readings are temperature dependent (up to $3 \%$ change $/{ }^{\circ} \mathrm{C}$ ) and field measured resistance should be corrected for differences between calibration and field temperatures. Some reading devices contain manual or self-compensating features for temperature or the manufacture provides correction charts or equations. Measurement range is $0.3-2.0$ bar (Fig. 10).

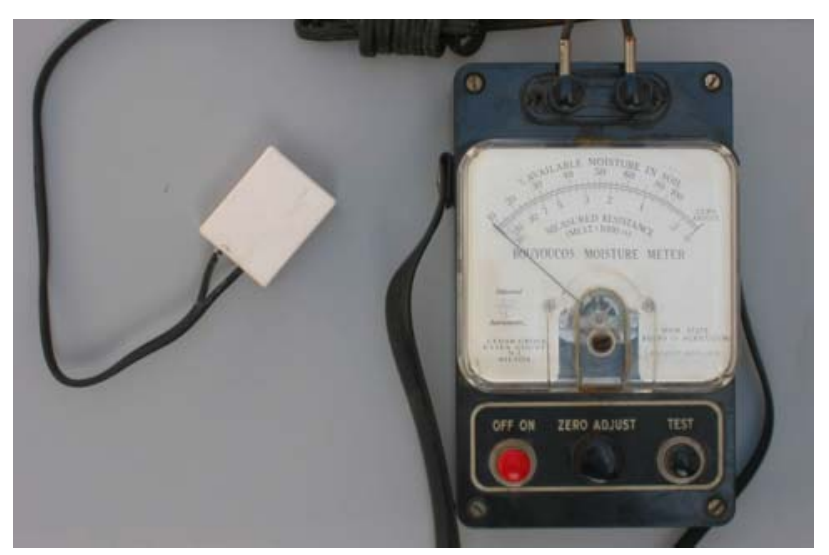

Figure 10. Gypsum block.
Advantages

- Up to 4 inch measurement cylinder radius

- No maintenance needed

- Simple and inexpensive

- Salinity effects buffered up to $6 \mathrm{dS} / \mathrm{m}$

- Well suited for irrigation where only "full" and "refill" points are required

- Suited to regulated-deficit irrigation

Drawbacks

- Low resolution, limited use in research

- Block cannot be used for measurements around saturation ( $0-0.3$ bar)

- Block properties change with time, because of clay deposition and gypsum dissolution. Degradation speed depends on soil type, amount of rainfall and irrigation, and also the type of gypsum block used

- Very slow reaction time. It does not work well in sandy soils, where water drains more quickly than the instrument can equilibrate

- Not suitable for swelling soils

- Inaccurate readings due to the block hysteresis (i.e., at a fixed soil water potential, the sensor can display different resistance when wetting than when drying)

- Temperature dependent. If connected to a logging system, another variable and sensor for temperature must be added to the system

\section{Granular Matrix Sensors (GMS)}

Description: The sensor consists of electrodes embedded in a granular quartz material, surrounded by a synthetic membrane and a protective stainless steel mesh. Inside, gypsum is used to buffer against salinity effects. This kind of porous medium allows for measuring in wetter soil conditions and lasts longer than the gypsum blocks. However, even with good sensor-soil contact, GMS have rewetting problems after they have been dried to very dry levels. This is because of the reduced ability of water films to re-enter the coarse medium of the GMS from a fine soil. The GMS material allows for measurements closer to saturation. Measurement range is $0.10-2.0$ bar (Fig. 11). 


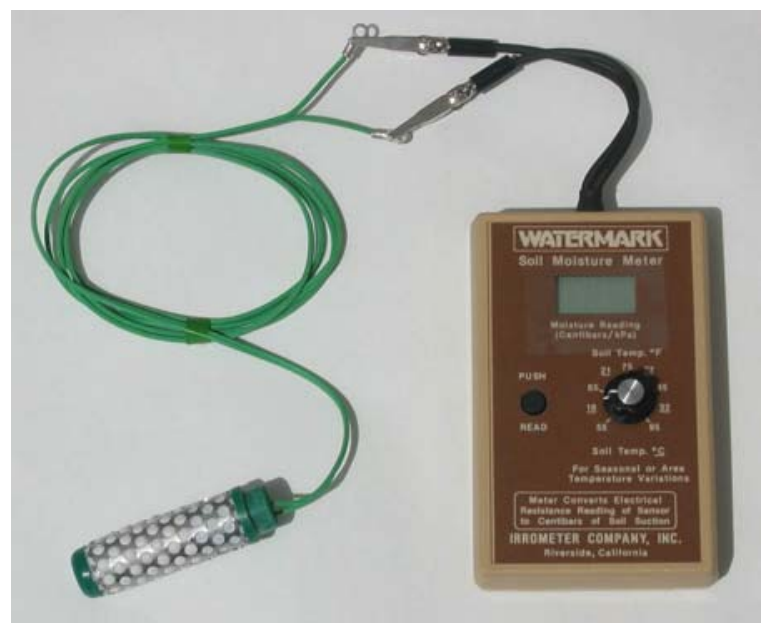

Figure 11. GMS sensor.

\section{Advantages}

- Reduces the problems inherent to gypsum blocks (i.e., loss of contact with the soil by dissolving, and inconsistent pore size distribution)

- Up to 4 inch measurement cylinder radius

- No maintenance needed

- Simple and inexpensive

- Salinity effects buffered up to $6 \mathrm{dS} / \mathrm{m}$

- Suited to regulated-deficit irrigation

Drawbacks

- Low resolution, limited use in research

- Slow reaction time. It does not work well in sandy soils, where water drains more quickly than the instrument can equilibrate

- Not suitable for swelling soils

- If the soil becomes too dry, the sensor must be pulled out, re-saturated and installed again

- $\quad$ Temperature dependence. If connected to a logging system, another variable and sensor for temperature must be added to the system

\section{Heat Dissipation}

Working principle: The thermal conductivity of water produces heat dissipation, so that a dry material will heat up faster than a wet one. In other words, the heat flow in a porous material is proportional to its water content.

Description: A thermal heat probe consists of a porous block containing a heat source and an accurate temperature sensor. The block temperature is measured before and after the heater is powered for a few seconds. Thereby, block moisture is obtained from the temperature variation. Since the porous block, placed in contact with the soil, is equilibrated with the soil water, its characteristic curve will give the soil water potential. Hence, the sensor must be provided with the calibrated relationship between the measured change in temperature and soil water potential. Measurement range: 0.1-30 bar (less accurate for 10-30 bar range) (Fig. 12).

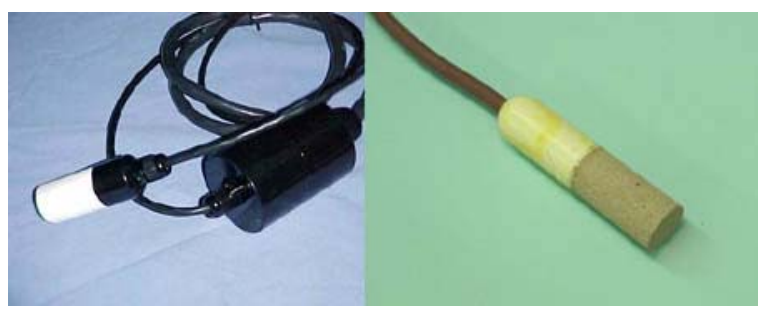

Figure 12. Heat dissipation sensor.

\section{Advantages}

- Wide measurement range

- No maintenance required

- Up to 4 inch measurement cylinder radius

- Continuous reading possible

- Not affected by salinity because measurements are based on thermal conductivity

\section{Drawbacks}

- Needs a sophisticated controller/logger to control heating and measurement operations

- Slow reaction time. It does not work well in sandy soils, where water drains more quickly than the instrument can equilibrate

- Fairly large power consumption for frequent readings

\section{Soil Psychrometer}

Working principle: Under vapour equilibrium conditions, water potential of a porous material is directly related to the vapour pressure of the air surrounding the porous medium. This means that the soil water potential is determined by measuring the $R H$ of a chamber inside a porous cup equilibrated with the soil solution (Campbell and Gardner, 1971). 
Description: A soil psychrometer consists of a ceramic shield or screen building an air chamber, where a thermocouple is located. The screen type is recommended for high salinity environments. $R H$ in the air chamber is calculated from the "wet bulb" vs "dry bulb" temperature difference. Measurement range: 0.5-30 bar (less accurate for 10-30 bar range) (Fig. 13).
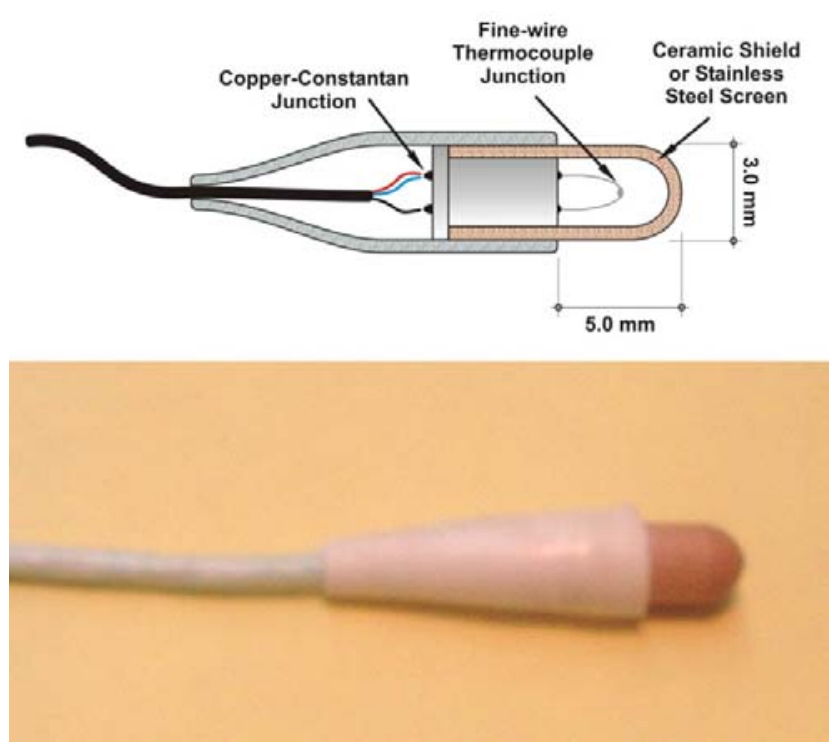

Figure 13. Soil psychrometer.

Advantages

- High sensitivity

- Scientifically rigorous readings (except in wetter soil conditions)

- $\quad$ Suitable where typical moisture conditions are very dry

Drawbacks

- Not recommended at shallow soil depths, due to high susceptibility to thermal gradient

- Small sensing volume

- Very slow reaction time, because reaching vapour equilibrium takes time

- Low accuracy in the wet range

- Specialized equipment is required for the sensor's excitation and reading

\section{Recommendations and Future Outlook}

As described above, there is a wide range of available methods for measuring and monitoring soil water content. Often, the selection of a technique is not simple, because all methods present advantages and disadvantages, which can be important in the particular situation. The selection of a suited method should take into consideration several issues:

- Soil properties (texture, organic matter content, swelling, heterogeneity)

- Application (irrigation scheduling, monitoring, research)

- $\quad$ Plant type (if present)

- Accuracy and moisture range needed

- Cost (capital and annual cost)

- Skill level required for operation

- Maintenance

Table 1 and Table 2 display a comparison of the methods presented to provide the reader with a quick reference.

Charlesworth (2000) presents a Value Selection Method suggested by Cape (1997) to decide which soil moisture measuring technique is most applicable to a particular situation. This procedure consists of answering a number of questions $($ Yes $=1$, No $=0)($ Table 3$)$. The relative importance of each question is quantified with appropriate weights, and a total relative importance (T) of each sensor for a specific application is obtained by adding the individual scores from all questions and multiplying it by the score for the "effective range of measurement" criterion. This multiplication factor ( 0 or 1$)$ is a modification of the original method proposed here. This implies that no sensor will be valid for an application if the field measuring range does not match the sensor's specifications. The total estimated life cost of the sensor (Cost) is estimated from capital, installation, running, and maintenance costs for the expected life of the sensor (L). The annual cost (A) of the sensor is obtained by Cost divided by $\mathrm{L}(\mathrm{A}=\operatorname{Cost} / \mathrm{L})$. The final sensor value for the application $(\mathrm{V})$ is obtained by $\mathrm{T}$ divided by $\mathrm{A}$ (T/A). 
The device with the highest value $\mathrm{V}$ is more suited to the needs and budget considered. An illustration example is included in Table 3 where the neutron probe is compared with an FDR sensor. Both alternatives include measuring moisture at one point with ten depths. The FDR equipment includes a logger and software for graphical desplay of information as standard and the neutron probe a built-in display where the moisture values can be read after input of the site-specific calibration, in addition to the count number. For the example application, both devices satisfy the criteria (score $=1$ ) of range of measurement, accuracy, reliability and data handling. On the other hand $($ score $=0)$, the FDR calibration is strongly dependent on soil type, whereas the neutron probe does not allow for quick/frequent readings, does not provide datalogging since it cannot be left unattended in the field and needs a strict maintenance program as a radioactive device. Although the cost of installation is similar (both are tubes in the ground), the total cost of the neutron probe is higher, as is the data-collection labor (requires certified personnel). The expected life for both devices is 10 years. The Value Selection Method indicates that FDR is a superior option for this application.

In the context of soil water monitoring, because of the soil's natural and man-induced variability, location and number of instruments may be crucial. Several factors can affect soil moisture reading variability: soil type and intrinsic heterogeneity, plant growth variation, rainfall interception, reduced application efficiency and uniformity in irrigation, etc. Hence, in general, it is recommended to identify the average (representative) conditions in terms of soil type, depth, plant distribution, sources of water (if irrigation), and place the instruments in each representative zone.

Since the pressure to manage water more prudently and efficiently is increasing, it is expected that research on soil water measurement will continue to produce reliable and low-cost solutions. Future research should focus on developing new techniques or improving the available actual methods to overcome the main limitation of requiring a soil-specific calibration. From a research perspective, a combined device that provides both volumetric and tensiometric in-situ readings would be desirable, since these two state variables are often needed in many mass transport studies. Further refinement of non-contact and remote sensing techniques shows promise to evaluate soil moisture distribution and variation across large scales.

\section{References}

Alvarez-Benedí, J. and R. Muñoz-Carpena (eds). 2004. Soil - Water - Solute processes in environmental systems. Monitoring, characterization and modeling. CRC Press LLC: Boca Raton. (in press).

Campbell, G.S. and W.H. Gardner, 1971. Psychrometric measurement of soil water potential: temperature and bulk density effects. Soil Sci. Soc. Am. Proc. 35: 8-12.

Cape, J. 1997. A value selection method for choosing between alternative soil moisture sensors. Project No. AIT2, Land and Water Resources Research and Development Corporation Report.

Charlesworth, P. 2000. Soil water monitoring. National Program for Irrigation Research and Development. CSIRO Land and Water. 101 p.

Dane, J.H. and G.C. Topp. 2002. The soil solution phase. In J.H. Dane and G.C. Topp (eds), Methods of Soil Analysis, Part 4: Physical Methods, Chapter 3. Soil Science Society of America, Inc., Madison, WI.

Davis, J.L. and A.P. Annan. 2002. Ground penetrating radar to measure soil water content. Pages 446-463. In: J.H. Dane and G.C. Topp (eds) Methods of Soil Analysis, Part 4: Physical Methods. Soil Science Society of America, Inc., Madison, WI.

Gaskin, G.D. and J.D. Miller, 1996. Measurement of soil water content using simplified impedance measuring technique. Journal of Agricultural Engineering Research 63: 153-160. 
Muñoz-Carpena, R., Y. Li and T. Olczyk. 2002.

Alternatives for low cost soil moisture monitoring devices for vegetable production in the south Miami-Dade County agricultural area. Fact Sheet ABE 333, Florida Cooperative Extension Service, Institute of Food and Agricultural Sciences, University of Florida, 6 p.

Muñoz-Carpena, R., H. H. Bryan, W. Klassen, and M.D. Dukes. 2003. Automatic Soil MoistureBased Drip Irrigation for Improving Tomato Production. Proceedings of the Florida State Horticulatural Society 116:80-85.

Nakashima, M., M. Inoue, K. Sawada and C. Nicholl. 1998. Measurement of soil water content by amplitude domain reflectometry (ADR) method and its calibrations. Chikasui Gakkaishi (Bulletin of the Japanese Association of Groundwater Hydrology) 40: 509-519.

Robinson, D.A., C.M.K. Gardner and J.D. Cooper. 1999. Measurement of relative permittivity in sandy soils using TDR, Capacitance and Theta Probe: comparison, including the effect of bulk soil electrical conductivity. Journal of Hydrology 223: 198-211.

Topp, G.C., Davis, J.L. and Annan, A.P. 1980. Electromagnetic determination of soil water content: measurements in coaxial transmission lines. Water Resources Research 16, 574-582.

Wijaya, K., T. Nishimura and K. Makoto. 2002. Estimation of bulk density of soil by using amplitude domain reflectometry (ADR) probe. $17^{\text {th }}$ WCSS. Thailand. Paper no. 385.

Yoder, R.E., D.L. Johnson, J.B. Wilkerson and D.C. Yoder. 1998. Soil water sensor performance. Applied Engineering in Agriculture 14(2): 121-133. 


\section{Tables}

Table 1. Evaluation criteria for volumetric soil water monitoring methods.

\begin{tabular}{|c|c|c|c|c|c|c|}
\hline & $\begin{array}{c}\text { Neutron } \\
\text { Moderation }\end{array}$ & TDR & $\begin{array}{c}\text { FD } \\
\text { (Capacitance } \\
\text { and FDR) } \\
\end{array}$ & ADR & $\begin{array}{c}\text { Phase } \\
\text { Transmission }\end{array}$ & TDT \\
\hline Reading range & $0-0.60 \mathrm{ft}^{3} \mathrm{ft}^{-3}$ & $\begin{array}{c}0.05-0.50 \mathrm{ft}^{3} \mathrm{ft}^{-3} \\
\text { or } 0.05-\text { Saturation } \\
\text { (with soil specific } \\
\text { calibration) }\end{array}$ & 0-Saturation & 0-Saturation & $0.05-0.50 \mathrm{ft}^{3} \mathrm{ft}^{-3}$ & $\begin{array}{l}0.05-0.50 \mathrm{ft}^{3} \mathrm{ft}^{-3} \\
\text { or } 0-0.70 \mathrm{ft}^{3} \mathrm{ft}^{-3} \\
\text { Depending on } \\
\text { instrument }\end{array}$ \\
\hline $\begin{array}{l}\text { Accuracy (with soil- } \\
\text { specific calibration) }\end{array}$ & $\pm 0.005 \mathrm{ft}^{3} \mathrm{ft}^{-3}$ & $\pm 0.01 \mathrm{ft}^{3} \mathrm{ft}^{-3}$ & $\pm 0.01 \mathrm{ft}^{3} \mathrm{ft}^{-3}$ & $\pm 0.01-0.05 \mathrm{ft}^{3} \mathrm{ft}^{-3}$ & $\pm 0.01 \mathrm{ft}^{3} \mathrm{ft}^{-3}$ & $\pm 0.05 \mathrm{ft}^{3} \mathrm{ft}^{-3}$ \\
\hline $\begin{array}{l}\text { Measurement } \\
\text { volume }\end{array}$ & $\begin{array}{l}\text { Sphere (6-16 } \\
\text { in. radius) }\end{array}$ & $\begin{array}{l}\text { about } 1.2 \text { in. radius } \\
\text { around length of } \\
\text { waveguides }\end{array}$ & $\begin{array}{l}\text { Sphere } \\
\text { (about } 1.6 \text { in. } \\
\text { effective } \\
\text { radius) }\end{array}$ & $\begin{array}{c}\text { Cylinder } \\
\text { (about } 1.2 \text { in.) }\end{array}$ & $\begin{array}{c}\text { Cylinder } \\
\text { (4-5 galllons) }\end{array}$ & $\begin{array}{c}\text { Cylinder }(0.2-1.6 \\
\text { gallons) of } 2 \text { in. } \\
\text { radius }\end{array}$ \\
\hline Installation method & Access tube & $\begin{array}{l}\text { Permanently } \\
\text { buried in situ or } \\
\text { inserted for manual } \\
\text { readings }\end{array}$ & $\begin{array}{c}\text { Permanently } \\
\text { buried in situ } \\
\text { or PVC access } \\
\text { tube }\end{array}$ & $\begin{array}{l}\text { Permanently } \\
\text { buried in situ or } \\
\text { inserted for } \\
\text { manual readings }\end{array}$ & $\begin{array}{l}\text { Permanently } \\
\text { buried in situ }\end{array}$ & $\begin{array}{l}\text { Permanently } \\
\text { buried in situ }\end{array}$ \\
\hline Logging capability & No & $\begin{array}{l}\text { Depending on } \\
\text { instrument }\end{array}$ & Yes & Yes & Yes & Yes \\
\hline Affected by salinity & No & High levels & Minimal & No & $>3 \mathrm{dS} / \mathrm{m}$ & At high levels \\
\hline $\begin{array}{l}\text { Soil types not } \\
\text { recommended }\end{array}$ & None & $\begin{array}{l}\text { Organic, dense, } \\
\text { salt or high clay } \\
\text { soils }\end{array}$ & None & None & None & $\begin{array}{l}\text { Organic, dense, } \\
\text { salt or high clay } \\
\text { soils (depending } \\
\text { on instrument) }\end{array}$ \\
\hline Field maintenance & No & No & No & No & No & No \\
\hline Safety hazard & Yes & No & No & No & No & No \\
\hline Application & $\begin{array}{l}\text { Irrigation, } \\
\text { Research, } \\
\text { Consultants }\end{array}$ & $\begin{array}{l}\text { Irrigation, } \\
\text { Research, } \\
\text { Consultants }\end{array}$ & $\begin{array}{l}\text { Irrigation, } \\
\text { Research }\end{array}$ & $\begin{array}{l}\text { Irrigation, } \\
\text { Research }\end{array}$ & Irrigation & Irrigation \\
\hline $\begin{array}{l}\text { Cost (includes } \\
\text { reader/loggerl } \\
\text { interface if } \\
\text { required) }\end{array}$ & $\$ 10,000-15,000$ & $\$ 400-23,000$ & $\$ 100-3,500$ & $\$ 500-700$ & $\$ 200-400$ & $\$ 400-1,300$ \\
\hline
\end{tabular}


Table 2. Evaluation criteria for tensiometric soil water monitoring methods.

\begin{tabular}{|c|c|c|c|c|c|}
\hline & Tensiometer & Gypsum block & GMS & Heat dissipation & $\begin{array}{c}\text { Soil } \\
\text { psychrometer }\end{array}$ \\
\hline Reading range & $0-0.80$ bar & $0.3-2.0$ bar & $0.1-2.0$ bar & $0.1-10$ bar & $0.5-30$ bar \\
\hline $\begin{array}{l}\text { Accuracy (with soil- } \\
\text { specific calibration) }\end{array}$ & \pm 0.01 bar & \pm 0.01 bar & \pm 0.01 bar & $\begin{array}{l}7 \% \text { absolute } \\
\text { deviation }\end{array}$ & \pm 0.2 bar \\
\hline Measurement volume & $\begin{array}{c}\text { Sphere } \\
\text { (>4 in. radius) }\end{array}$ & $\begin{array}{c}\text { Sphere } \\
\text { (>4 in. radius) }\end{array}$ & $\begin{array}{c}\text { Sphere } \\
\text { (about } 0.8 \text { in. } \\
\text { radius) }\end{array}$ & & $\begin{array}{c}\text { Sphere } \\
\text { (>4 in. radius) }\end{array}$ \\
\hline Installation method & $\begin{array}{l}\text { Permanently } \\
\text { inserted into } \\
\text { augered hole }\end{array}$ & $\begin{array}{l}\text { Permanently } \\
\text { inserted into } \\
\text { augered hole }\end{array}$ & $\begin{array}{l}\text { Permanently } \\
\text { inserted into } \\
\text { augered hole }\end{array}$ & $\begin{array}{l}\text { Permanently } \\
\text { inserted into } \\
\text { augered hole }\end{array}$ & $\begin{array}{l}\text { Permanently } \\
\text { inserted into } \\
\text { augered hole }\end{array}$ \\
\hline Logging capability & $\begin{array}{l}\text { Only when using } \\
\text { transducers }\end{array}$ & Yes & Yes & Yes & Yes \\
\hline Affected by salinity & No & $>6 \mathrm{dS} / \mathrm{m}$ & $>6 \mathrm{dS} / \mathrm{m}$ & No & $\begin{array}{c}\text { Yes, for ceramic } \\
\text { cup type } \\
\text { (use screen type) }\end{array}$ \\
\hline $\begin{array}{l}\text { Soil types not } \\
\text { recommended }\end{array}$ & $\begin{array}{l}\text { Sandy or coarse } \\
\text { soils }\end{array}$ & $\begin{array}{l}\text { Sandy or coarse } \\
\text { soils, avoid } \\
\text { swelling soils }\end{array}$ & $\begin{array}{l}\text { Sandy or coarse } \\
\text { soils, avoid } \\
\text { swelling soils }\end{array}$ & Coarse & $\begin{array}{c}\text { Sandy or coarse } \\
\text { soils, avoid } \\
\text { swelling soils }\end{array}$ \\
\hline Field maintenance & Yes & No & Medium & No & No \\
\hline Safety hazard & No & No & No & No & No \\
\hline Application & $\begin{array}{l}\text { Irrigation } \\
\text { Research }\end{array}$ & Irrigation & Irrigation & $\begin{array}{l}\text { Irrigation } \\
\text { Research }\end{array}$ & Research \\
\hline $\begin{array}{l}\text { Cost (includes } \\
\text { reader/loggerl } \\
\text { interface if required) }\end{array}$ & $\$ 75-250$ & $\$ 400-700$ & $\$ 200-500$ & $\$ 300-500$ & $\$ 500-1,000$ \\
\hline
\end{tabular}


Table 3. Example of an application of Value Selection Method to choose between alternative soil moisture sensors (modified from Cape, 1997). The point value for each attribute in column (b) is given in parenthesis in the Attributes column. The score in column (c) is calculated for each attribute by multiplying the Point in column (b) with the Weight assigned to that attribute in column (a). More explanation is given in the text.

\begin{tabular}{|c|c|c|c|c|c|c|}
\hline \multirow[b]{2}{*}{ Attributes } & & \multirow[b]{2}{*}{$\begin{array}{l}\text { Weight } \\
\text { (a) }\end{array}$} & \multicolumn{2}{|c|}{ Neutron probe } & \multicolumn{2}{|c|}{ FDR } \\
\hline & & & $\begin{array}{l}\text { Point } \\
\text { (b) }\end{array}$ & $\begin{array}{c}\text { Score } \\
\text { (c) }\end{array}$ & $\begin{array}{l}\text { Point } \\
\text { (b) }\end{array}$ & $\begin{array}{l}\text { Score } \\
\text { (c) }\end{array}$ \\
\hline $\begin{array}{l}\text { Effective range of } \\
\text { measurement } \\
\text { (Point: Yes }=1 ; \text { No }=0 \\
\text { sensor is not recommended } \\
\text { for application and Total } \\
\text { score } T=0 \text { ) }\end{array}$ & $\begin{array}{l}\text { Is the soil water sensor (sws) able to measure all } \\
\text { ranges of soil water of interest to you? }\end{array}$ & - & 1 & & 1 & \\
\hline $\begin{array}{l}\text { Accuracy } \\
\text { (Point: } \text { Yes }=1 ; \text { No }=0)\end{array}$ & $\begin{array}{l}\text { Is the sensor accuracy enough for your } \\
\text { purpose? }\end{array}$ & 14 & 1 & 14 & 1 & 14 \\
\hline $\begin{array}{l}\text { Soil types (for use with } \\
\text { range of soils) } \\
\text { (Point: Yes = } 0 ; \text { No = 1) }\end{array}$ & $\begin{array}{l}\text { Is the sensor's accuracy affected by the soil } \\
\text { type? }\end{array}$ & 11 & 1 & 11 & 0 & 0 \\
\hline $\begin{array}{l}\text { Reliability } \\
\text { (Point: Yes = } 1 ; \text { No = } 0)\end{array}$ & $\begin{array}{l}\text { Do you have any personal, other users' or } \\
\text { literature-based idea of the reliability of the } \\
\text { sensor, and is the failure rate satisfactory to } \\
\text { you? }\end{array}$ & 13 & 1 & 13 & 1 & 13 \\
\hline $\begin{array}{l}\text { Frequency/soil disturbance } \\
(\text { Point: } Y e s=1 ; \text { No }=0)\end{array}$ & $\begin{array}{l}\text { Can the sensor provide quick or frequent } \\
\text { readings in undisturbed soil? }\end{array}$ & 8 & 0 & 0 & 1 & 8 \\
\hline $\begin{array}{l}\text { Data handling } \\
\text { (Point: Yes = } 0 ; \text { No = 1) }\end{array}$ & $\begin{array}{l}\text { Will you have difficulty in reading or interpreting } \\
\text { data? }\end{array}$ & 8 & 1 & 8 & 1 & 8 \\
\hline $\begin{array}{l}\text { Communication (for remote } \\
\text { data manipulation) } \\
\text { (Point: Yes }=1 ; \text { No }=0)\end{array}$ & $\begin{array}{l}\text { Does the sensor provide data logging and } \\
\text { downloading capabilities and friendly software } \\
\text { for analyzing and interpreting the data? }\end{array}$ & 10 & 0 & 0 & 1 & 10 \\
\hline $\begin{array}{l}\text { Operation and maintenance } \\
\text { (Point: Give the sensor } 1 / 4 \text { for } \\
\text { each Yes answer; No = } 0 \text { ) }\end{array}$ & $\begin{array}{l}\text { Is the sensor calibration universal? } \\
\text { Does the sws have a long life ( }>5 \text { years }) ? \\
\text { Is the sensor maintenance free? } \\
\text { Is the sensor easy to install? }\end{array}$ & 10 & $\begin{array}{c}0 \\
0.25 \\
0 \\
0.25\end{array}$ & $\begin{array}{c}0 \\
2.5 \\
0 \\
2.5\end{array}$ & $\begin{array}{l}0 \\
0.25 \\
0.25 \\
0.25\end{array}$ & $\begin{array}{c}0 \\
2.5 \\
2.5 \\
2.5\end{array}$ \\
\hline $\begin{array}{l}\text { Safety } \\
\text { (Point: Yes = 0; No = 1) }\end{array}$ & Does use of the sensor entail any danger? & 8 & 0 & 0 & 1 & 8 \\
\hline \multicolumn{3}{|l|}{ Total (T) } & & 51 & & 68.5 \\
\hline \multicolumn{3}{|l|}{ Cost (Cost) (in \$) } & & 15000 & & 7500 \\
\hline \multicolumn{3}{|l|}{ Life (L) (in years) } & & 10 & & 10 \\
\hline \multicolumn{3}{|c|}{ Annual cost of sensor ( $\mathbf{A}=$ Cost $/ L)$ (in \$/year) } & & 1500 & & 750 \\
\hline \multicolumn{3}{|l|}{ Value of sensor $(V=T / A)$} & & 0.034 & & 0.091 \\
\hline
\end{tabular}

